\title{
The influence of alkali-resistant glass fibres on properties of fine-aggregate concretes
}

\author{
Lucyna Domagała ${ }^{1, *}$, Ewelina Bizoń-Żabińska, and Kamil Kurzyniec ${ }^{1}$ \\ ${ }^{1}$ Cracow University of Technology, ul. Warszawska 24, Cracow 31-155, Poland
}

\begin{abstract}
The aim of this paper is to assess the effect of modification of fine-aggregate concrete properties with zirconia alkali-resistant glass fibres. Three types of fine-aggregate composites were subject to tests: normal-weight concretes made of natural sand, non-foamed and foamed lightweight concretes made of expanded glass aggregate. The concretes were modified with the glass fibres mainly in quantities ranged from 1.0 to $5.0 \mathrm{~kg} / \mathrm{m}^{3}$. Even such low contents resulted in the increase of both flexural and compressive strength, by up to $45 \%$ and $26 \%$, respectively. In the case of normal-weight fine-aggregate concretes the applied glass fibres turned out to be especially effective in improvement of the properties in early ages. At the age of 28 days both types of concretes revealed similar percentage strength increase. In comparison to HP $12 \mathrm{~mm}$ the application of longer fibres (HP $24 \mathrm{~mm}$ ) led to slightly higher results of flexural strength tests. On the other hand, the shorter fibres were definitely more effective in the improvement of compressive strength due to their greater number and more uniform dispersion in concrete volume. The used contents of alkali-resistant glass fibres did affect neither density nor water absorption of the hardened concretes.
\end{abstract}

\section{Introduction}

Fine-aggregate concretes are commonly used for production of precast thin-walled elements e.g. flat and curvilinear claddings, facade panels, hollow blocks, pipes, elements of linear drainage, exterior and interior stucco as well as elements of small architecture [1-4]. To reduce the dead load of the products and/or to enhance their thermal insulation lightweight fine-aggregate concretes are often used instead of normal-weight ones. Moreover, the lightweight concretes applied to wall elements revealed better sound absorption, fire and freeze-thaw resistance [5-8].

Small wall thickness of these products, in many cases as low as $10 \mathrm{~mm}-30 \mathrm{~mm}$, often makes it impossible not only to use a typical concrete containing coarse aggregate for their production, but also to reinforce them with steel rods or mesh. On the other hand, in comparison to a typical fine and coarse aggregate concrete, meeting the requirements of EN 206 [9], the fine-aggregate concrete is characterised by a higher binder content, resulting in a higher shrinkage, creep and generally higher susceptibility to deformations [10-12]. All this makes it necessary to reinforce fine-aggregate concrete used for the production of thin-walled elements with short, flexible fibres, which are able to improve the structural integrity of the material.

In practice polypropylene and glass fibres are mostly applied as reinforcement for fine-aggregate concretes used in thin-walled products. Both types are flexible and easy to disperse uniformly in thin elements making the composite structure homogeneous with well finished surface. However, glass fibres, due to their density comparable to that of natural aggregate, are less susceptible to float on the top surface of an element. Both fibre types are used in order to limit shrinkage of cement composites and control resulting cracking. Nevertheless, glass fibres are much more effective in reduction of all types of volume changes, including these caused by loading. In result, they prevent cement composites from cracking and deformations more efficiently. Moreover, in contrast to polypropylene fibres, glass fibres may considerably improve mechanical properties of composites [13-20]. It has been proven that the fibres may cause the increase of tensile, flexural and shear strength of concretes and mortars. Moreover, concretes reinforced with glass fibres reveal improved resistance to abrasion and dynamic loads. Some of research has shown that the application of glass fibres may even lead to the improvement in compressive strength. The compressive strength increase was mainly achieved at relatively low water-binder ratio $(0.20-$ 0.35 ) when glass fibres dosages ranged from $1.0 \%$ to $3.0 \%$ of mix volume $[13-14,16,20]$. On the other hand the research reported in [15] has shown that a certain increase of compressive strength is even possible at quantities of glass fibres as small as $0.1-0.3 \%$ of mix volume. It should be noted that polypropylene and even steel fibres, used in such volume dosages, do not influence the compressive strength due to their relatively low tensile strength and modulus of elasticity or their small number in a composite volume [21].

Corresponding author: ldomagala@pk.edu.pl 
The high effectiveness of glass fibres in enhancement of mechanical properties is connected with their specific properties. Glass fibres reveal tensile strength as high as $1700-2500 \mathrm{MPa}$. These values even exceed the tensile strength of steel fibres $(500-2000 \mathrm{MPa})$ and are several times higher than the tensile strength of polypropylene fibres $(250-600 \mathrm{MPa})$. At the same time the number of glass fibres in a volume unit of concrete is incomparably greater than in the case of application of steel fibres and considerably greater even in relation to polypropylene fibres. Moreover, modulus of elasticity of glass fibres $(70-80 \mathrm{GPa})$ is significantly higher than that of polypropylene ones $(3-7 \mathrm{GPa})$.

Especially high performance of concrete is expected when it is modified with alkali-resistant glass fibres. These high performance fibres are produced of a special type of glass containing zirconia. The zirconia oxide $\left(\mathrm{ZrO}_{2}\right)$ content of $16 \%-19 \%$ makes fibres alkaliresistant and prevent a composite from degradation resulting from reaction between alkali from cement and silica from glass. Moreover, this type of fibres, as more resistant to chemical attack, is especially applied for concretes subject to acidic or highly alkaline exposure.

Since glass fibres are especially effective in thinwalled members, the term Glass Fibre Reinforced Concrete (GRC or GFRC) is usually limited just to the material composed of natural sand, glass fibres and cement paste, with or without the incorporation of admixtures and additions. By that means GRC was defined in standards EN 1169 and EN 1170 [22-23] dedicated to precast products made of glass fibre reinforced concrete. When fine aggregate is lightweight or coarse aggregate is additionally used a composite is usually not regarded as GRC. This is the reason why glass fibre content in GRC is typically expressed in \% of composite weight. Meanwhile, in the case of the other types of concrete reinforced with fibres their content is usually given in percentage of concrete volume or simply in mass units per 1 cubic meter of concrete. The general recommendations for glass fibre content expressed in \% of composite weight are useless particularly in the case of lightweight concretes.

\section{Experimental details}

The main aim of the research was to assess the effect of modification of properties of fine-aggregate concretes of different types with zirconia alkali-resistant glass fibres. The fibres were expected to enhance cohesion of fresh concretes as well as strength properties in hardened state.

Additional objectives of the research were:

- to determine the effect of a fibre length on properties of selected fine-aggregate concretes;

- to assess the strength development of selected fineaggregate concretes in time.

\subsection{Materials and mix compositions}

Tests were carried out on three types of fine-aggregate concretes: normal-weight, non-foamed and foamed lightweight fine-aggregate concretes. All concrete types are commonly used for thin-walled products.

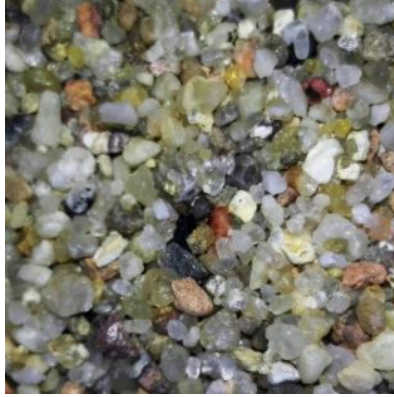

Natural sand $0 / 2 \mathrm{~mm}$

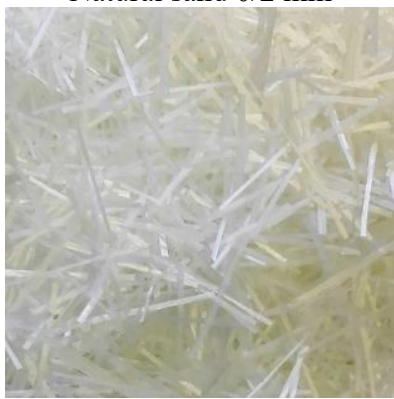

Fibres HP 12 mm

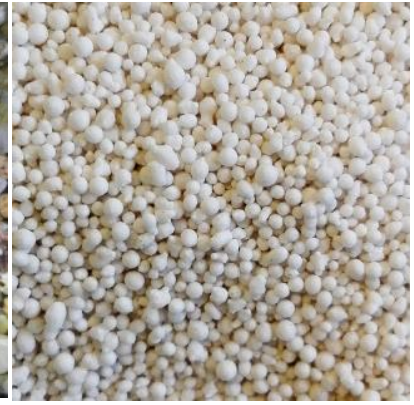

Expanded glass $0.25 / 1.0 \mathrm{~mm}$

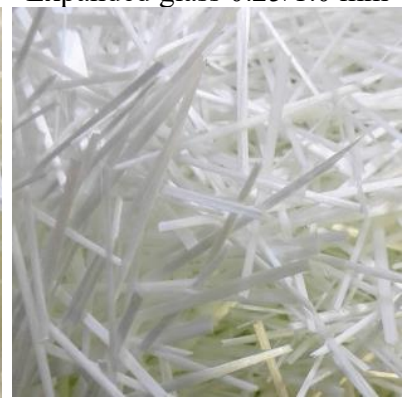

Fibres HP $24 \mathrm{~mm}$
Fig. 1. Fine aggregates and fibres used for made concretes.

In the case of normal-weight concretes the ovendried quartzite standard sand $0 / 2 \mathrm{~mm}$ with a particle density of $2650 \mathrm{~kg} / \mathrm{m}^{3}$ was used as the fine aggregate. For lightweight concretes expanded glass aggregate Penostek 0.25/1.0 mm was applied. The glass aggregate was composed of two separated fractions: $0.25 / 0.5 \mathrm{~mm}$ and $0.5 / 1.0 \mathrm{~mm}$ in mass proportions of $1: 5$. The particle density was $700 \mathrm{~kg} / \mathrm{m}^{3}$ and $510 \mathrm{~kg} / \mathrm{m}^{3}$ respectively for fractions $0.25 / 0.5 \mathrm{~mm}$ and $0.5 / 1.0 \mathrm{~mm}$. To limit water absorption in fresh concrete the lightweight aggregate was initially wetted to the moisture content of $14 \%$. Such a treatment guaranteed a constant workability of fresh lightweight fine - aggregate concrete, comparable to the workability of mixtures containing fine nonabsorbent quartzite aggregate.

Two types of high performance zirconia alkaliresistant glass fibres were used: Cem-fil ${ }^{\circledR}$ Anti$\mathrm{Crack}^{\mathrm{TM}}$ HP $12 \mathrm{~mm}$ and HP $24 \mathrm{~mm}$ [24]. Fibres of both lengths are used to reinforced fine-aggregate concretes for thin-walled elements. The applied fibres are characterized with following parameters: diameter - 14 $\mu \mathrm{m}$, density $-2680 \mathrm{~kg} / \mathrm{m}^{3}$, modulus of elasticity -72 $\mathrm{GPa}$. The fibre producer declares that these chopped strands may improve mechanical properties of concrete and mortars. Fibre dosages recommended for concrete are following: $0.9-1.5 \mathrm{~kg} / \mathrm{m}^{3}$ in the case of welded wire reinforcement replacement; $1.5-5.0 \mathrm{~kg} / \mathrm{m}^{3}$ in the case of welded wire reinforcement and/or rebars \#3, \#4 replacement; $5.0-15.0 \mathrm{~kg} / \mathrm{m}^{3}$ in the case of structural reinforcement replacement. For mortars the recommended dosage varies from between $0.2 \%$ to 1.0 $\%$ by weight [24]. For the purpose of this research a fibre content was generally assumed from the range of 0 to 5 $\mathrm{kg} / \mathrm{m}^{3}$. These are typical quantities of fibres usually used 
for fine-aggregate concrete to reduce its shrinkage and prevent thin-walled elements from damage at transportation, tooling and installation. Only for one mixture the fibre dosage of $15 \mathrm{~kg} / \mathrm{m}^{3}$ was applied. These mass contents correspond to the percentage volume content of 0 to $0.2 \%$ and $0.6 \%$, respectively. In the case of the applied normal-weight fine-aggregate concretes these values are very similar to percentage mass contents related to mix weight.

Both types of fine-aggregates and alkali-resistant glass fibres used for the concretes are presented in figure 1.

The other basic constituent materials were: Portland cement CEM I $32.5 \mathrm{R}$, tap water and admixtures. Superplasticizer was used in a dosage suitable to ensure similar workability of mixtures. Therefore, the admixture content has been increased together with an increasing dosage of fibres. In the case of some lightweight fineaggregate concretes (mixes LAC and 1FLAC - 5FLAC), characterised by high water-binder ratio, foaming admixture was applied to stabilise the structure of composites.

Table 1. Compositions of fine-aggregate concretes

\begin{tabular}{|c|c|c|c|c|c|}
\hline \multirow[b]{2}{*}{ Mix } & \multicolumn{5}{|c|}{ Constituent material content in $\mathrm{kg} / \mathrm{m}^{3}$} \\
\hline & $\begin{array}{c}\text { Fine } \\
\text { aggregate }\end{array}$ & Cement & Water & Admixture & Fibres \\
\hline & $\begin{array}{c}\text { Natural } \\
\text { sand }\end{array}$ & & & $\begin{array}{c}\text { Super- } \\
\text { plasticizer }\end{array}$ & $\begin{array}{c}\mathrm{HP} \\
12 \mathrm{~mm} \\
\end{array}$ \\
\hline $\mathrm{NC}$ & 1535 & 512 & 256 & 0.0 & 0.0 \\
\hline $1 \mathrm{FNC}$ & 1534 & 512 & 255 & 0.5 & 1.0 \\
\hline $2 \mathrm{FNC}$ & 1533 & 512 & 254 & 1.5 & 2.0 \\
\hline $3 \mathrm{FNC}$ & 1532 & 512 & 253 & 2.5 & 3.0 \\
\hline $4 \mathrm{FNC}$ & 1531 & 512 & 253 & 3.1 & 4.0 \\
\hline $5 \mathrm{FNC}$ & 1530 & 512 & 252 & 3.6 & 5.0 \\
\hline \multirow[t]{2}{*}{$15 \mathrm{FNC}$} & 1520 & 512 & 243 & 12.6 & 15.0 \\
\hline & $\begin{array}{c}\text { Natural } \\
\text { sand }\end{array}$ & & & $\begin{array}{c}\text { Super- } \\
\text { plasticizer }\end{array}$ & $\begin{array}{c}\mathrm{HP} \\
24 \mathrm{~mm} \\
\end{array}$ \\
\hline $1 \mathrm{FFNC}$ & 1534 & 512 & 256 & 0.3 & 1.0 \\
\hline $2 \mathrm{FFNC}$ & 1533 & 512 & 255 & 0.8 & 2.0 \\
\hline $3 \mathrm{FFNC}$ & 1532 & 512 & 254 & 1.5 & 3.0 \\
\hline 4FFNC & 1531 & 512 & 254 & 2.0 & 4.0 \\
\hline \multirow[t]{2}{*}{ 5FFNC } & 1530 & 512 & 253 & 2.5 & 5.0 \\
\hline & $\begin{array}{c}\text { Expand. } \\
\text { Glass, } \\
\text { m.c. }=14 \%\end{array}$ & & & $\begin{array}{c}\text { Super- } \\
\text { plasticizer }\end{array}$ & $\begin{array}{c}\mathrm{HP} \\
12 \mathrm{~mm}\end{array}$ \\
\hline $\mathrm{LC}$ & 352 & 512 & 255 & 0.5 & 0.0 \\
\hline \multirow[t]{2}{*}{ 3FLC } & 351 & 512 & 253 & 2.5 & 3.0 \\
\hline & $\begin{array}{c}\text { Expand. } \\
\text { Glass, } \\
\text { m.c. }=14 \%\end{array}$ & & & $\begin{array}{c}\text { Foaming } \\
\text { agent }\end{array}$ & $\begin{array}{c}\mathrm{HP} \\
12 \mathrm{~mm}\end{array}$ \\
\hline LAC & 352 & 335 & 271 & 0.8 & 0.0 \\
\hline 1FLAC & 352 & 335 & 271 & 0.8 & 1.0 \\
\hline 2FLAC & 352 & 335 & 271 & 0.8 & 2.0 \\
\hline 3FLAC & 351 & 335 & 271 & 0.8 & 3.0 \\
\hline 4FLAC & 351 & 335 & 271 & 0.8 & 4.0 \\
\hline 5FLAC & 351 & 335 & 271 & 0.8 & 5.0 \\
\hline
\end{tabular}

Compositions of all 20 fine-aggregate concretes to be tested are given in Table 1. Most concrete mixtures were characterised by the water-binder ratio of 0.50 . In the case of above-mentioned six foamed lightweight concretes the water-binder ratio was as high as 0.81 . For normal-weight fine-aggregate concretes a standard mortar corresponding to the requirements of EN 196-1 [25] was a reference composite (mix NC). Reference lightweight concretes (mix LC and LAC) had the same aggregate and cement paste volume share as the reference concrete for normal-weight composites $(58 \%$ : $42 \%)$.

\subsection{Testing methods}

All fresh concretes were subject to consistence tests according to EN 1015-3 [26]. Additionally, stability of mixtures, their workability and finishability were visually assessed.

In the case of hardened concretes density in saturated and oven-dried state in accordance to the rules of EN 12390-7 [27] as well as flexural and compressive strength in accordance to EN 196-1 [25] were tested. For all tests in hardened state specimens with sizes of $4 \mathrm{x} 4 \mathrm{x}$ $160 \mathrm{~mm}$ were prepared. Density and flexural strength were tested on 3 beams, while compressive strength on 6 halves of beams. The procedure of test specimens preparation was similar to this applied for moulding products of glass fibres concrete. In relation to the procedure described in EN 196-1 [25] the rate of mixing was constant, fibres were added in the end of mixing, specimens were moulded in one layer and compaction was made on a vibration table. All hardened concretes were tested after 28 days of standard curing. Additionally for selected series (mix NC, 3FNC, LAC, 3FLAC) tests were carried out at the age of 2 and 7 days.

\section{Results and discussion}

\subsection{Consistence and stability of mixtures}

The reference composite for normal-weight fineaggregate concretes (mix NC) revealed the flow of 150 $\mathrm{mm}$. As it was expected, addition of fibres made the mixtures less workable. Therefore, in order to obtain a suitable reference workability it was necessary to modify the compositions of the mixtures by superplasticizer. Its content was dependent on a content and a type of fibres.

In the case of fibres HP $12 \mathrm{~mm}$ used in dosages of $1.0-5.0 \mathrm{~kg} / \mathrm{m}^{3}$ superplasticizer was used in moderate quantities of $0.10-0.70 \%$ of cement mass. However, application of fibres in dosage as high as $15.0 \mathrm{~kg} / \mathrm{m}^{3}$ (mix 15FNC) required as high admixture content as 2.5 $\%$ of cement mass.

When longer fibres (HP $24 \mathrm{~mm}$ ) were used the applied superplasticizer dosages may have been respectively lower $(0.06-0.50 \%$ of cement mass $)$ in comparison to mixtures containing the same content of fibres HP $12 \mathrm{~mm}$. Better workability of mixtures modified with the longer fibres resulted from their lower number in mass unit and lower ability to disperse uniformly in mixture. The bundles of HP $12 \mathrm{~mm}$ seemed to disperse to single fibres immediately after dosing (fig. 
2), while HP $24 \mathrm{~mm}$ remained in clusters for a longer time.

Lightweight mixture 3FLC, modified by the same superplasticizer quantity as the corresponding normalweight concrete (3FNC), resulted in comparable workability. However, its consistence measurement tested by the flow table method was smaller $(126 \mathrm{~mm})$ due to a lower density of the mixture, which was less able to flow.

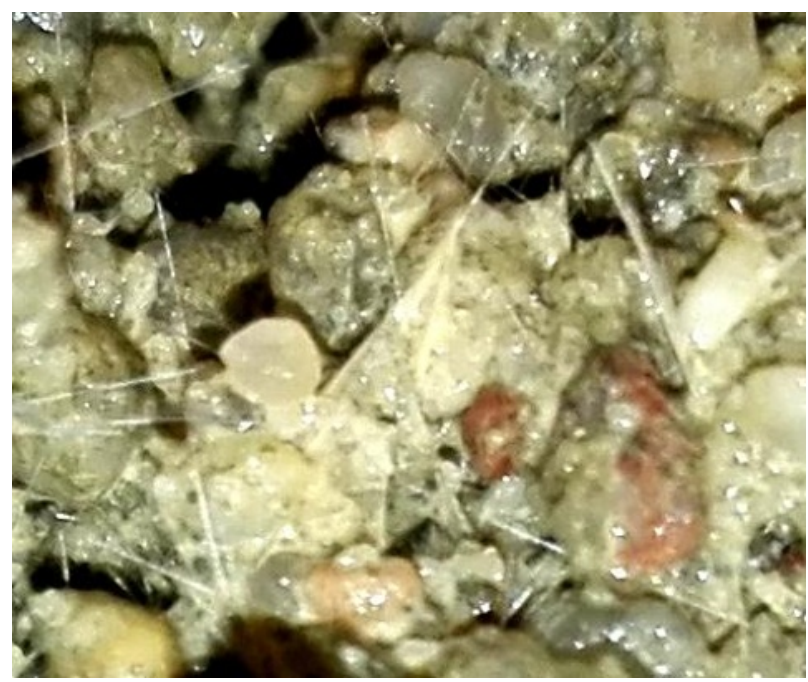

Fig. 2. Uniform dispersion of fibres HP $12 \mathrm{~mm}$ at the beginning of mixing.

The foaming agent used for lightweight concretes of $\mathrm{w} / \mathrm{c}=0.81$, irrespective of fibre content, made the mixtures workable enough not to additionally modify them by superplasticizer. Moreover, all the mixtures hardly required to be compacted despite the fact that their flow, depending on a fibre content, ranged between $138 \mathrm{~mm}$ and $165 \mathrm{~mm}$. Generally, the consistence measurements of lightweight fine-aggregate concrete by the flow table method seem to be connected with its workability to a lesser extent than those in the case of normal-weight composite.

Excluding mixture $15 \mathrm{FNC}$, the modification of fineaggregate concretes with glass fibres improved their stability and finishability in fresh state and made the mixtures less susceptible to bleeding and constituents segregation. This aspect of glass fibre application was crucial in the case of concretes containing expanded glass aggregate significantly lighter than the cement paste.

\subsection{Density and water absorption}

The density of reference hardened concretes in water saturated state was: $2280 \mathrm{~kg} / \mathrm{m}^{3}, 1150 \mathrm{~kg} / \mathrm{m}^{3}$ and 870 $\mathrm{kg} / \mathrm{m}^{3}$, respectively for $\mathrm{NC}, \mathrm{LC}$ and LAC. Corresponding oven-dried density was: $2140 \mathrm{~kg} / \mathrm{m}^{3}, 850 \mathrm{~kg} / \mathrm{m}^{3}$ and 620 $\mathrm{kg} / \mathrm{m}^{3}$. The results of density tests make it possible to assess the water absorption of the concretes at: $6.5 \%$, $35.3 \%$ and $40.3 \%$, respectively. These values illustrate to some extent the differences in porosity structure of various reference concretes.
Modification of the reference concretes with fibres did not significantly affect the density in both states: water saturated and oven-dried. The glass fibre reinforced concretes revealed the density higher at the most by $10 \mathrm{~kg} / \mathrm{m}^{3}$ in relation to a corresponding reference concrete. The effect of fibres on water absorption of the concretes was also negligible.

\subsection{Flexural strength}

The mean results of flexural strength tests of 28 day normal-weight fine-aggregate concretes are presented in figures 3 and 4. The values ranged from 6.4 MPa up to 8.5 MPa. The standard deviation was from the range of 0 to $0.3 \mathrm{MPa}$ and seemed to be dependent on neither a content nor a type of fibres. All concretes modified with fibres in a quantity of $1.0-5.0 \mathrm{~kg} / \mathrm{m}^{3}$, irrespective to their type (HP $12 \mathrm{~mm}$ or $24 \mathrm{~mm}$ ), showed the visible strength increase. The increase ranged from $7 \%$ up to 16 $\%$ and was the highest at the fibre content of $3.0 \mathrm{~kg} / \mathrm{m}^{3}$. Exceeding this dosage of fibres the flexural strength gradually decreased. This tendency may be explained by higher dosages of superplasticizer used for increased content of fibres and air-entraining side effect of this admixture application. In result, at the fibre content of 15 $\mathrm{kg} / \mathrm{m}^{3}$ and superplasticizer dosage of $2.5 \%$ of cement mass the $12 \%$ decrease of flexural strength was observed. Similarly, the slightly higher strength results of some concretes reinforced with longer fibres (HP 24 $\mathrm{mm})$ may have resulted from a lower superplasticizer content.

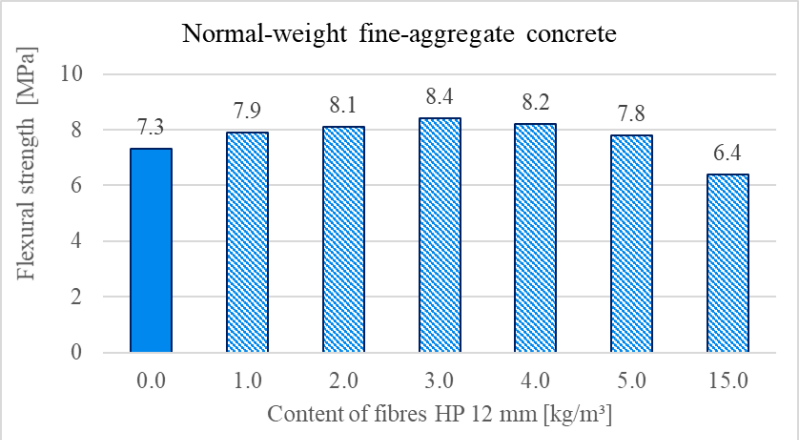

Fig. 3. Mean 28-day flexural strength of normal-weight fineaggregate concrete, not modified and modified with fibres HP $12 \mathrm{~mm}$.

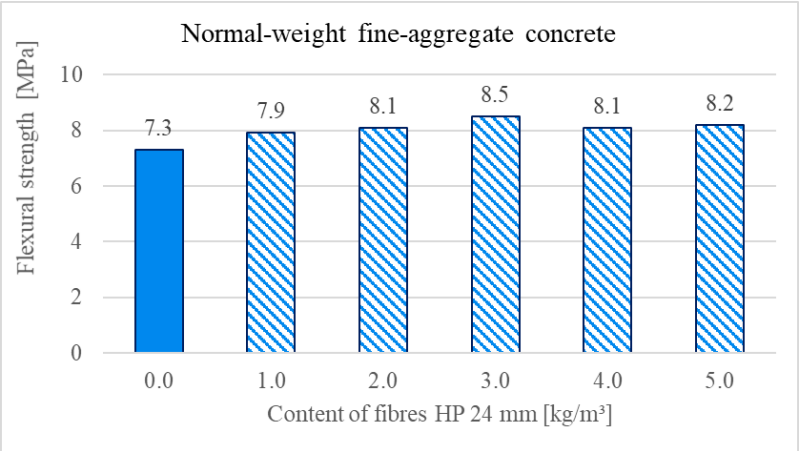

Fig. 4. Mean 28-day flexural strength of normal-weight fineaggregate concrete, not modified and modified with fibres HP $24 \mathrm{~mm}$. 
Nevertheless, the primary reasons of possibly higher effectiveness of longer fibres are probably their greater slenderness and ratio of a fibre length to an aggregate size.

The mean results of flexural strength tests of 28 day lightweight fine-aggregate concretes, presented in figures 5 and 6 , ranged from $1.8 \mathrm{MPa}$ up to $3.6 \mathrm{MPa}$. The standard deviation was from the range of 0 to 0.2 $\mathrm{MPa}$. In the case of lightweight fine-aggregate concretes the influence of glass fibres was not so visible due to generally significantly lower strength values. Nevertheless, the increase of flexural strength of foamed concretes changed in almost the same percentage range as for normal-weight concretes. Application of fibres for non-foamed lightweight concrete resulted in slightly lower percentage strength increment.

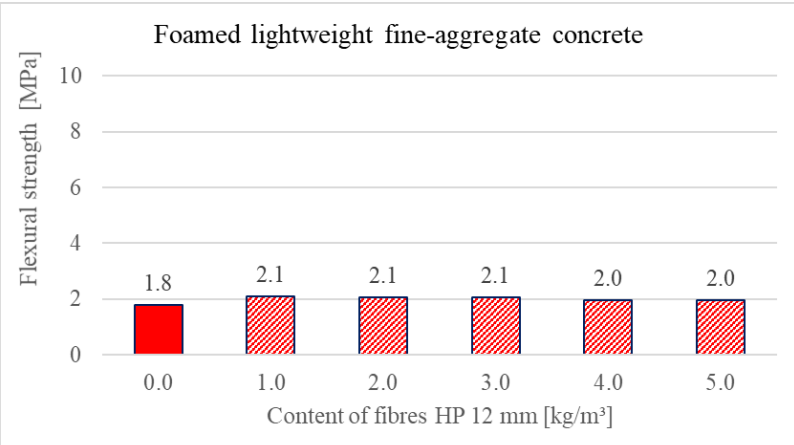

Fig. 5. Mean 28-day flexural strength of foamed lightweight fine-aggregate concrete, not modified and modified with fibres HP $24 \mathrm{~mm}$.

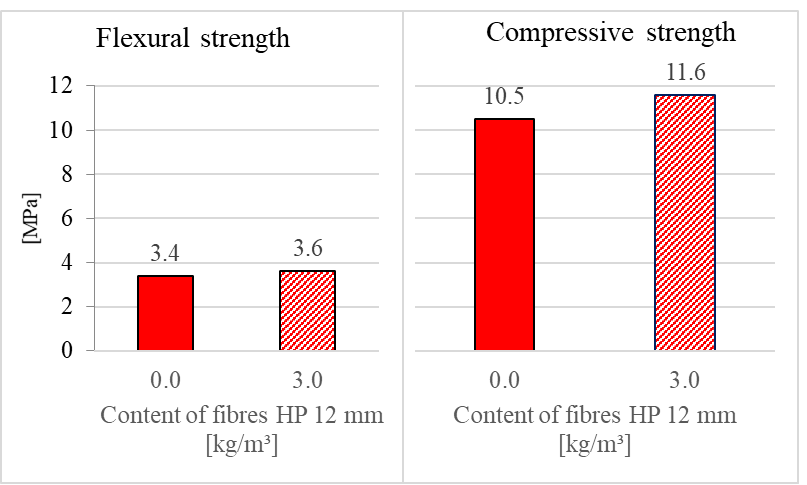

Fig. 6. Mean 28 day flexural and compressive strength of nonfoamed lightweight fine-aggregate concrete, not modified and modified with fibres HP $12 \mathrm{~mm}$.

Analysing the development of flexural strength of fine-aggregate concretes in time, presented in figure 7, it should be noted that the effectiveness of fibre application differs for concretes in a different age. At the age of 2 days the normal-weight concrete revealed the flexural strength increase as high as $45 \%$, while at the age of 7 and 28 days the corresponding increment was merely 24 $\%$ and $15 \%$, respectively. The especially high effectiveness of application of fibres in early ages resulted from relatively low flexural strength of cement paste. In later ages developing its strength the cement matrix was able to participate more efficiently in transfer of tensile stresses. In the case of lightweight concretes, probably due to their very low strength values, the effect of concrete reinforcement with fibres was not observed in early ages. The other explanation of this observation may be not sufficient adhesion of highly porous cement paste to the fibres in the first days of curing.

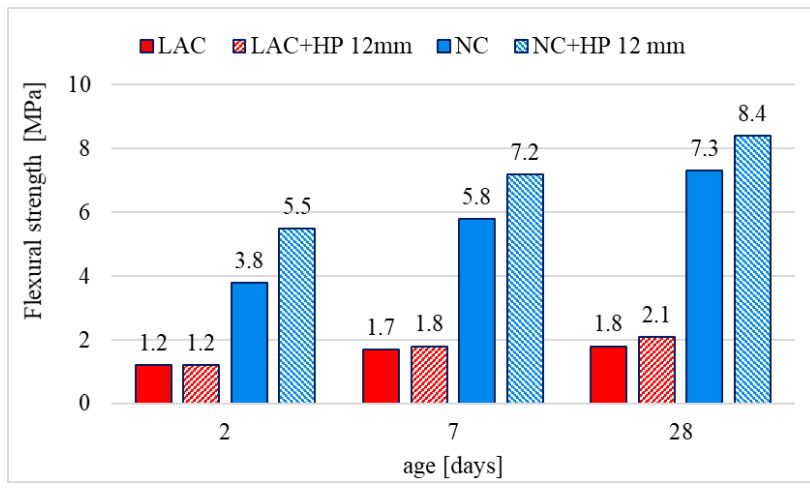

Fig. 7. The development of mean flexural strength of foamed lightweight fine-aggregate concrete (LAC) and normal-weight fine-aggregate concrete (NC), not modified and modified with $3 \mathrm{~kg} / \mathrm{m}^{3}$ of fibres HP $12 \mathrm{~mm}$.

\subsection{Compressive strength}

The mean results of compressive strength tests of 28 day normal-weight fine-aggregate concretes are presented in figures 8 and 9 . The values ranged from $30.5 \mathrm{MPa}$ up to 48.7 $\mathrm{MPa}$. The standard deviation varied from $0.7 \mathrm{MPa}$ to $3.4 \mathrm{MPa}$ and like in the case of flexural strength seemed to be dependent on neither a content nor a type of fibres. The test results showed a tendency of a gradual increase in compressive strength as the content of fibres HP $12 \mathrm{~mm}$ and HP $24 \mathrm{~mm}$ increased from $1.0 \mathrm{~kg} / \mathrm{m}^{3}$ to $3.0 \mathrm{~kg} / \mathrm{m}^{3}$ or $4.0 \mathrm{~kg} / \mathrm{m}^{3}$, respectively. In the case of application of shorter fibres the highest increase was 17 $\%$, while for modification with longer fibres it was $11 \%$. Generally, in comparison to HP $12 \mathrm{~mm}$ the fibres HP 24 $\mathrm{mm}$, irrespective of their content, were less effective in compressive strength improvement. In the case of compressive strength its enhancement seems to be more dependent on a number of fibres and their uniform dispersion in concrete than a higher ratio of a fibre length to an aggregate size.

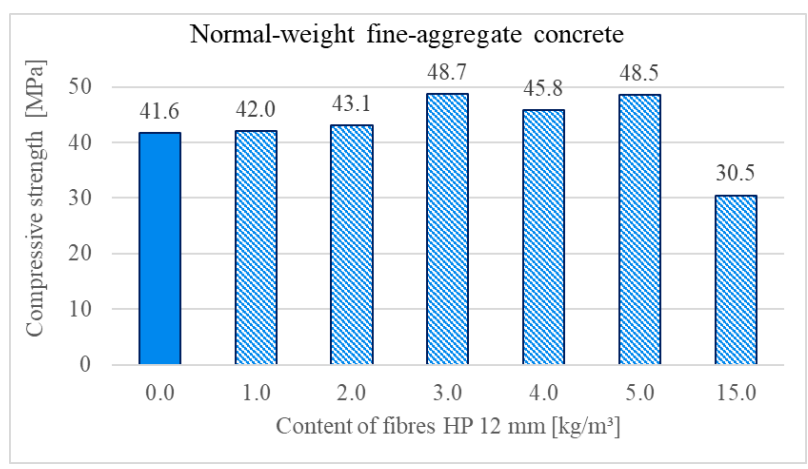

Fig. 8. Mean 28 day compressive strength of normal-weight fine-aggregate concrete, not modified and modified with fibres HP $12 \mathrm{~mm}$.

The fine-aggregate concrete containing as great quantity of fibres as $15 \mathrm{~kg} / \mathrm{m}^{3}$ revealed the decrease of 
compressive strength as high as $27 \%$ in relation to the reference concrete.

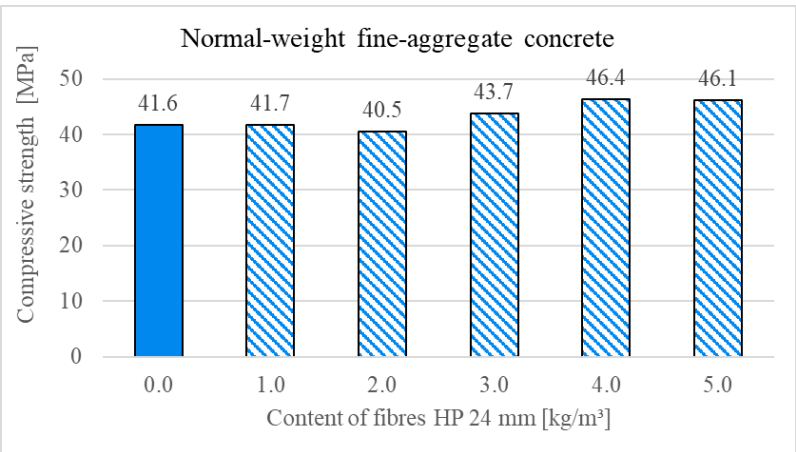

Fig. 9. Mean 28 days compressive strength of normal-weight fine-aggregate concrete, not modified and modified with fibres HP $24 \mathrm{~mm}$.

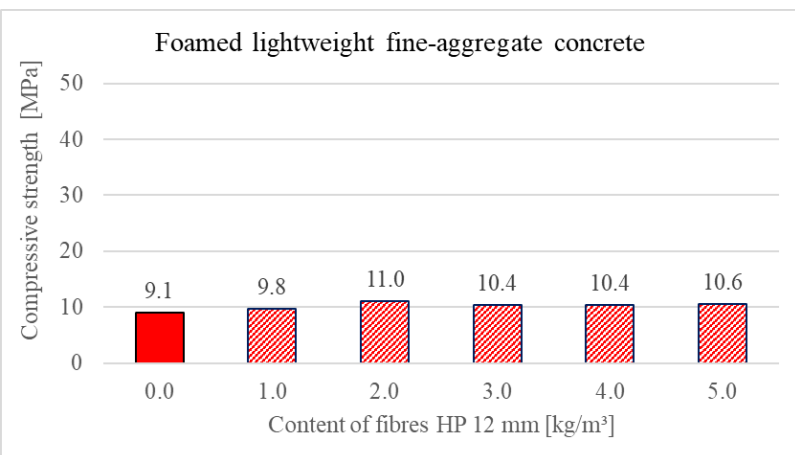

Fig. 10. Mean 28 days compressive strength of foamed lightweight fine-aggregate concrete, not modified and modified with fibres HP $24 \mathrm{~mm}$.

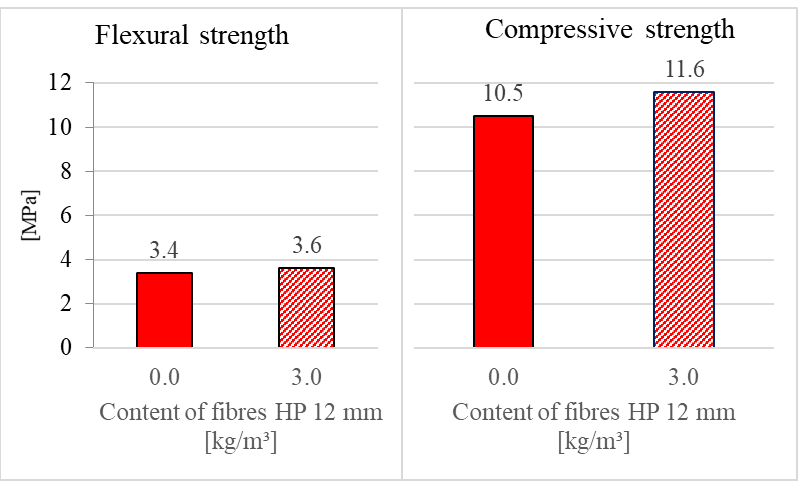

Fig. 11. Mean 28 days compressive and flexural strength of non-foamed lightweight fine-aggregate concrete, not-modified and modified with fibres HP $24 \mathrm{~mm}$.

The mean results of compressive strength tests of 28 day lightweight fine-aggregate concretes are presented in figures 10 and 11 . They ranged from 9.1 MPa up to 11.6 $\mathrm{MPa}$. The standard deviation varied from 0 to $0.4 \mathrm{MPa}$. In the case of lightweight fine-aggregate concretes the influence of glass fibres is hardly visible due to generally significantly lower strength values. Nevertheless, the maximum percentage compressive strength increase (by up to $21 \%$ ) is even higher than in the case of normalweight concretes. The application of fibres in a quantity of $3 \mathrm{~kg} / \mathrm{m}^{3}$ for non-foamed lightweight concrete resulted in a strength increment of $10 \%$ and was slightly less effective than that of the foamed lightweight concrete modified with the same dosage of fibres.

The development of compressive strength of fineaggregate concretes in time is presented in figure 12. As in the case of flexural strength, the compressive strength increase was the most effective in early ages. At the age of 2 days the normal-weight concrete revealed the increase in compressive strength as high as $26 \%$, while at the age of 7 and 28 days the corresponding increment was $22 \%$ and $17 \%$, respectively. In the case of foamed lightweight concretes, probably due to mentioned-above relatively low strength values and/or poor adhesion of porous cement paste to the fibres, the influence of concrete age is not so clear.

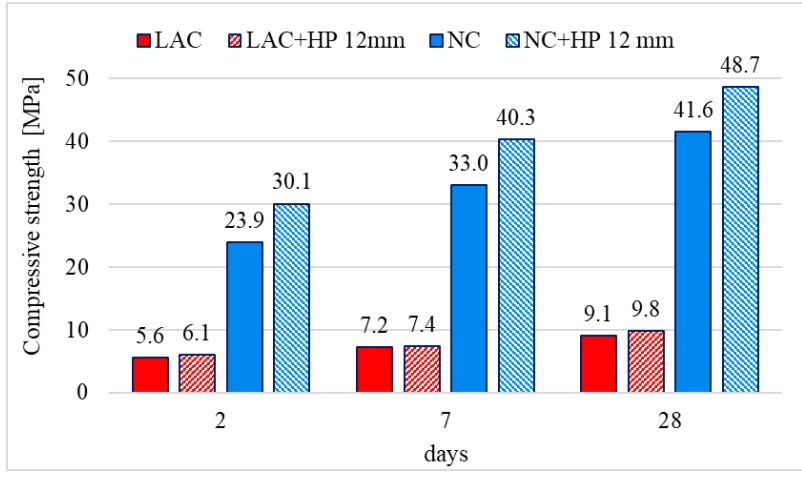

Fig. 12. Development of mean compressive strength of foamed lightweight fine-aggregate concrete (LAC) and normal-weight fine-aggregate concrete (NC), not-modified and modified with $3 \mathrm{~kg} / \mathrm{m}^{3}$ of fibres HP $12 \mathrm{~mm}$.

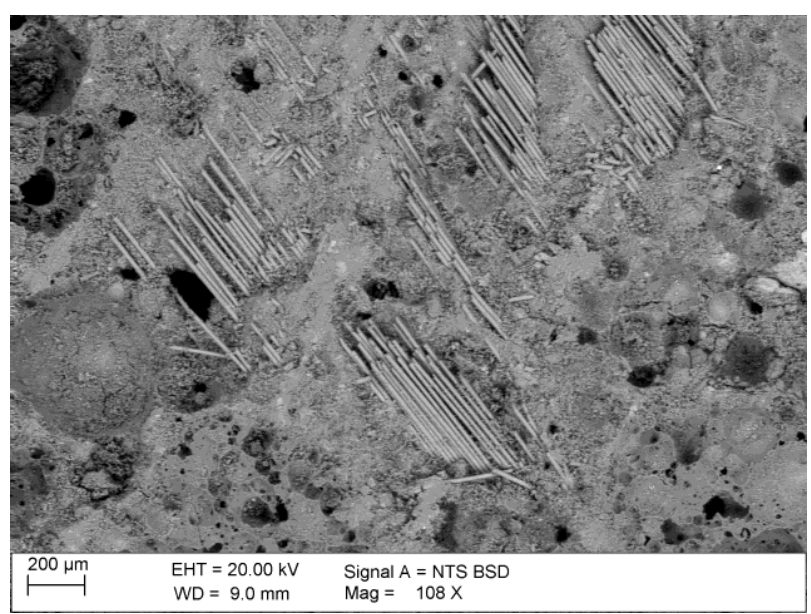

Fig. 13. SEM image of foamed lightweight fine-aggregate concrete reinforced with $12 \mathrm{~mm}$ zirconia glass fibres.

The analyse of the fracture of specimens subject to strength tests showed more uniform dispersion of fibres HP $12 \mathrm{~mm}$ in comparison to that of fibres HP $24 \mathrm{~mm}$. Nevertheless, despite the fact that fibres HP $12 \mathrm{~mm}$ were hardly visible without a microscope due to their effective dispersion, the SEM images showed that even these fibres may be found in bundles (fig. 13 and 14). Regardless of a length of fibres, their content, a type of fine aggregate as well as a type of strength test (flexural 
or compressive), the fibres rather lost their adhesion to the cement paste and were pulled out at failure of concrete than were broken off. No signs of fibre breakage were noticed. The observations of fracture under a scanning microscope confirmed the results of visual assessment.

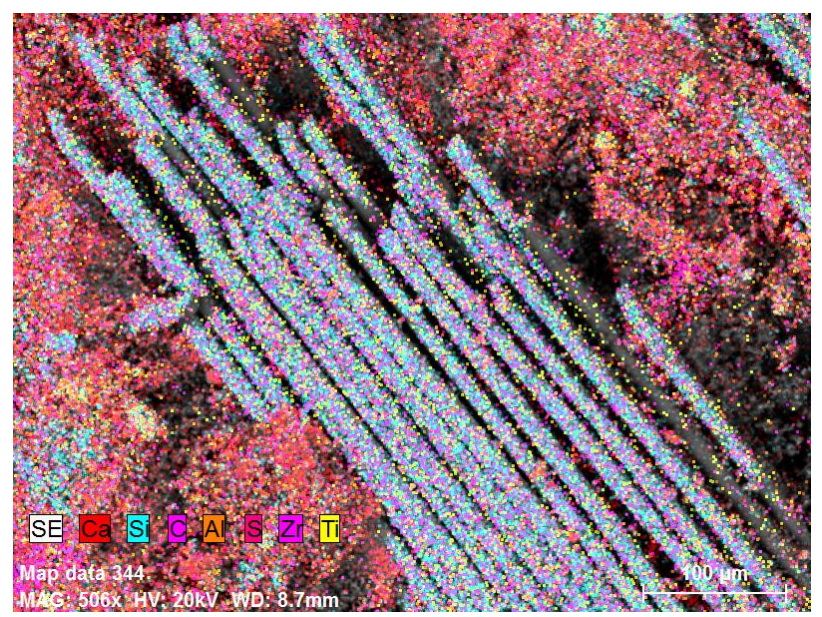

Fig. 14. EDS elemental mapping image of fine-aggregate concrete reinforced with zirconia glass fibres HP $12 \mathrm{~mm}$.

\section{Conclusions}

The carried out research and the analysis of the obtained results lead to the following conclusions:

- Alkali-resistant glass fibres in quantities as low as 1.0 - $5.0 \mathrm{~kg} / \mathrm{m}^{3}$ enhanced mechanical properties of fineaggregate concretes. In contrast to the other types of fibres used for concretes in comparable dosages, the fibres applied in this research improved not only the flexural strength, but the compressive one as well. The improvement of both types of strength is a result of very high tensile strength of alkali-resistant glass fibres as well as their good dispersion and significant number in a composite volume unit.

- The applied glass fibres turned out to be especially effective in improvement of the properties in early ages. The application of the fibres for normal-weight fine-aggregate concretes resulted in the increase of 2 day flexural strength as high as $45 \%$, while after 7 and 28 days the corresponding increase was $24 \%$ and 15 $\%$, respectively. In the case of compressive strength the increase after 2 days was up to $26 \%$, while after 7 and 28 days it was $22 \%$ and $17 \%$, respectively.

- The improvement of mechanical properties of lightweight fine-aggregate concretes was mainly observed in later ages. The maximum increase of flexural and compressive strength at the of age of 28 days was $17 \%$ and $21 \%$, respectively. The probable reasons of a poor effect of lightweight concrete reinforcement with the fibres in early ages are: generally low strength values and/or weak adhesion of foamed cement paste to the fibres in the first days of hydration.

- In comparison to HP $12 \mathrm{~mm}$ the application of longer fibres (HP $24 \mathrm{~mm}$ ) may lead to slightly higher results of flexural strength tests. On the other hand, the shorter fibres were definitely more effective in the improvement of compressive strength due to their greater number and more uniform dispersion in concrete volume.

- In respect of mechanical properties of fine-aggregate concretes the optimal content of fibres was about 3.0 $\mathrm{kg} / \mathrm{m}^{3}$. The application of higher contents of the fibres caused the necessity to increase superplasticizer dosages. This resulted in the decrease of strength. The fine-aggregate concrete containing as high quantity of fibres as $15 \mathrm{~kg} / \mathrm{m}^{3}$ and the highest, accepted by the producer, dosage of superplasticizer revealed poorer workability and the decrease of flexural and compressive strength of $22 \%$ and $27 \%$ respectively in relation to the reference concrete. A cement matrix of a different composition than that used in this research should be considered to apply such a high content of fibres.

- The fine-aggregate mixtures containing the alkaliresistant fibres in quantities of $1.0-5.0 \mathrm{~kg} / \mathrm{m}^{3}$ showed better workability at compaction than it could have been expected from the results of consistence measurements. A greater cohesion of fresh fineaggregate concretes reinforced with the glass fibres improved their finishability and prevented the composites from bleeding and component segregation. This is especially important aspect of fibre application in the case of lightweight aggregate concrete.

- The use of the fibres affected neither the density of fine-aggregate concretes nor their water absorption. However, it cannot be excluded that these fibres are able to efficiently improve the tightness of concrete and reduce its water absorption and permeability when it is subject to load and/or exposure that may cause cracking.

To sum up: the alkali-resistant glass fibres, even when they are used in quantities smaller than it is recommended by the manufacturer, may efficiently improve properties of both normal-weight and lightweight fine-aggregate concretes. It should be expected that the effectiveness of these fibres will be more pronounced in the case of concrete moulded in elements with walls thinner than $40 \mathrm{~mm}$ in comparison to that achieved on the standard beams.

\section{References}

1. Brooks A.J., Meijs M., Cladding in Buildings, Taylor \& Francis, Abingdon, (2008)

2. Henriksen T., Lo S., Knaack U., Advances in Civil Engineering Materials, 4 (2015)

3. Feirabend S., Emami A., Riedel E., Bautechnik, 91 (2014)

4. Henriksen T., Lo S., Knaack U., Journal of Building Engineering, 4 (2015)

5. Sharei E., Scholzen A., Hegger J., Chudoba R., Composite Structures, 171 (2017) 
6. Clarke J., Structural lightweight concrete, Chapman\&Hall, Glasgow, (1993)

7. Chandra S., Berntsson L., Lightweight aggregate concrete, Noyes Publications, New York, (2003)

8. Clarke J., Yaneske P., Building and Environment, 44 (2009)

9. EN 206 - Concrete - Specification, performance, production and conformity

10. Kucharczyková B., Šimonová H., Keršner Z., Daněk P., Kocáb D., Misák P., Pőssl P., Procedia Engineering, 190 (2017)

11. Neville A., Properties of concrete, Pearson Education Limited, Harlow (2018)

12. Mehta K., Monteiro P., Concrete microstructure, properties and materials. MCGraw Hill Education (2013)

13. Mirza F., Soroushiannd P., Cement and Concrete Composites, 24 (2002)

14. Tassew S., Lubell A., Construction and Building Materials, 51 (2014)

15. Ahmad S., Uma A., Journal of Building Engineering, 17 (2018)

16. Prasad M., Kumar P., Oshima T., International Journal of Mechanics and Solids , 4 (2009)

17. Mastali M., Dalvand A., Sattarifard A., Journal of Cleaner Production, 124 (2016)

18. Fenu L., Forni D., Cadoni E., Composites Part B: Engineering, 92 (2016)

19. Kharitonov A., Ryabova A., Pukharenko Y., Procedia Engineering, 165 (2016)

20. Yurdakul A., Dolekcekic E., Gunkaya G., Kavas T., Karasu B., Construction and Building Materials, 170 (2018)

21. Domagała L., Journal of Civil Engineering and Management, 17 (2011)

22. EN 1169 Precast concrete products - General rules for factory production control of glassfibre reinforced cement

23. EN 1170. Part 1 - 8. Precast concrete products. Test method for glass-fibre reinforced cement

24. http://www.ocvreinforcements.com/CemFil/pro -precast.aspx?lg=en (20.04.2018)

25. EN 196-1 Methods of testing cement. Determination of strength

26. EN 1015-3 Methods of test for mortar for masonry. Determination of consistence of fresh mortar (by flow table)

27. EN 12390-7 Testing hardened concrete. Density of hardened concrete 